Madhusudan Ghosh Regional Disparities in Education, Health and Human Development in India

Jandhyala B.G. Tilak What Matters for Outcomes in Elementary Education in India?

Pravat Kumar Kuri and Arindam Laha Financial Inclusion and Human Development in India: An Inter-State Analysis

Symposium on THE IDEA OF JUSTICE INDIAN Keith Dowding What Is the Idea of Justice?

Roberto Alejandro Towards a Hermeneutics of Justice: Reflections on Amartya Sen's Philosophy

Sebastiano Maffettone Sen's Idea of Justice versus Rawls' Theory of Justice

James P. Sterba What Sen Should Have Said to Rawls JOURNAL

Valerian Rodrigues Justice as the Lens: Interrogating Rawls through Sen and Ambedkar

Aakash Singh Rathore The Romance of Global Justice? Sen's Deparochialization and the Quandary of Dalit Marxism

Philip Pettit A Question for Sen about Democracy and Justice

Christian Schemmel Sen, Rawls - and Sisyphus

Evan Riley Against Sen Against Rawls on Justice

O.A. Oyeshile Sen's Realization-Focused Notion of Justice and the Burden of

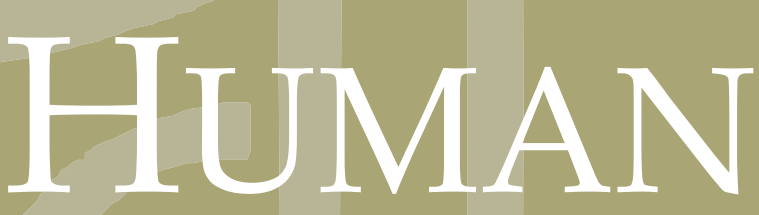
Democratic Governance in African Societies

PERSPECTIVE

Udaya S. Mishra On Adjusting the Survivorship Dimension in the Human Development Index

RESPONSE M.H. Suryanarayana New Estimates of Poverty in India: A Critique of the 'Tendulkar Committee Report' - A Response
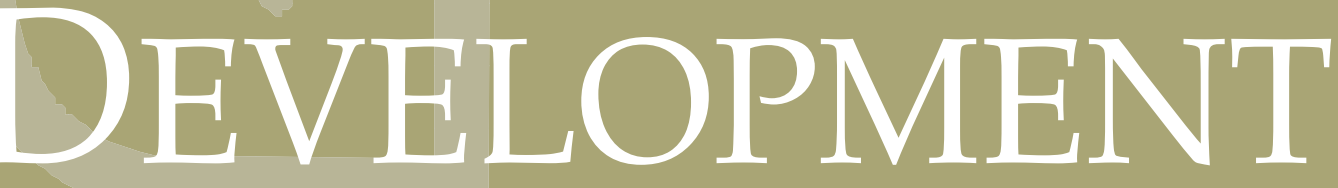

BOOK REVIEWS 


\title{
Sen's Idea of Justice versus Rawls' Theory of Justice
}

\author{
Sebastiano Maffettone*
}

\begin{abstract}
In 'The Idea of Justice', Amartya Sen presents an alternative approach to Rawls' theory of justice. The core argument is reformulated as a criticism of the neglect (by Rawls) of what Sen himself calls 'nyaya' in favour of the opposite 'niti.' According to Sen, Rawls' niti-centred approach, being merely institutional, under-estimates the necessary combination of just institutions and correspondent actual behaviours that make a society reasonably just. Sen consequently champions the opposite nyaya-centred approach, according to which 'what happens to people' must be a central concern for a theory of justice. To my advice, this argument is dependent on Sen's old idea, according to which the 'primary goods' basis of Rawls' approach to distributive justice is flawed and must be substituted by an approach in terms of capabilities. I instead think that the capability approach to a general theory of justice presents both epistemic and ethical problems of paramount importance. These problems are similar to the ones created by the necessity to rely on interpersonal comparisons when we move within the utilitarian tradition.
\end{abstract}

Keywords: The Idea of Justice, Amartya Sen, John Rawls

In his recent book, The Idea of Justice ${ }^{1}$, Amartya Sen presents a new theory of justice in polemics with the mainstream tradition. Sen's book is an enormously wideranging work and the domain of theories of justice that he refers to is complex and differentiated. There is no doubt, however, that the tradition of theories of justice that Sen has in mind has been inaugurated and dominated by the political philosophy of John Rawls. Therefore, it seems correct to conceive this book as an attempt to construct an alternative approach to Rawls' theory of justice. One could say that Sen tries to make a similar critical move against Rawls which the latter undertook, quite successfully, against utilitarianism in A Theory of Justice. In other words, Sen here attempts to put forward an alternative to the dominant theory of justice by critically engaging with it. Sen himself recognizes that Rawls' has been 'the most influential theory of justice in modern moral philosophy' (p. 59) and the second chapter of this book is devoted to 'Rawls and Beyond' (with the first chapter being mainly methodological). That is why it seems natural to assess the success of Sen's account in terms of the significance and effectiveness of his criticism of Rawls. To put it in the simplest way, did he present in this book a theory of justice, which shows Rawls' limitations in being able, at the same time, to exhibit a more powerful alternative. My answer to this question is 'No! He didn't.' The negative answer is, however, only partially negative. In fact, I think that Sen provides many arguments against Rawls' theory of justice, some of which rather persuasive. To be less vague, from my point of view, the core argument that Sen uses

* Professor, LUISS University, Rome. Email: maffettone@gmail.com 
against Rawls is not satisfying, but there are side arguments that can provide useful re-adjustments from within the Rawlsian paradigm and maybe even beyond it.

This core argument is elegantly reformulated as a criticism of the neglect (by Rawls) of what Sen himself calls in Sanskrit nyaya — following an Indian legacy-in favour of the opposite niti. The niti-nyaya distinction ranges over (at least) two disagreements. The first disagreement concerns the difference between the transcendental and the comparative: Rawls discusses what a perfectly just society should do, whereas for Sen, the most important problems that we need to confront are comparative problems, concerning ways of moving toward societies that are less unjust. The second disagreement concerns the role of institutions: for Rawls, justice is essentially about institutions and the particular distributions of goods are derivatively just if they are produced by just institutions; Sen, on the contrary, thinks that justice is essentially about how well or badly off individuals actually are. I do not see particular difficulties with the first disagreement. It is possible to consider actual unjust situations from a transcendental standpoint. That is why I will concentrate on the second disagreement.

According to Sen, Rawls' niti-centred approach, being merely institutional, underestimates the necessary combination of just institutions and correspondent actual behaviours that make a society reasonably just. Sen consequently champions the opposite nyaya-centred approach, according to which 'what happens to people' must be a central concern for a theory of justice. To my advice, this argument is dependent on Sen's old idea, according to which the 'primary goods' basis of Rawls' approach to distributive justice is flawed and must be substituted by an approach in terms of capabilities, even if curiously enough, Sen seems to think that this distinction is not so basic (p. 66). I instead think that the capability approach to a general theory of justice presents both epistemic and ethical problems of paramount importance. But before analysing these problems, we need to take a detour, given the complex nature of Sen's arguments against Rawls in this book.

I. To be fair (if this word can be so naively used here), Sen recognizes that several positive lessons can be learnt from the Rawlsian approach. He also ends the book by arguing that he forcefully distanced his own argument from that of Rawls due to his academic habit of emphasizing distinctions more than affinities, but that his real intention is, after all, to follow a parallel path ${ }^{2}$. For Sen, the main positive lessons to be learnt from Rawls are connected with the following points:

1. The idea that fairness is central to justice;

2. The thesis about the objectivity of practical reason;

3. The distinction between the 'reasonable' and the 'rational', and more generally, the reconstruction of the moral powers of persons as related to their capacity for a 'sense of justice' and a 'conception of the good';

4. The separate and over-riding concern for liberty (as compared with other primary goods);

5. The insistence on a 'fair equality of opportunities' as an enrichment of the literature on inequality; 
6. The need for according special attention to the worst-off people; and

7. The way in which primary goods are conceived, which gives people the opportunity to do what they would like with their own lives.

All these points permit us to say that Sen has in common with Rawls "an important shared involvement in being concerned with justice in the first place" (p. 413).

There are, of course, certain critical points that Sen sees in Rawls' theory of justice. Also Sen offers numerous criticisms of Rawls, so much so that sometimes we find it difficult to understand wherein lies the true difference between these two authors. Sen starts by separating what he calls 'problems that can be addressed effectively' ( $p$. 65), within the Rawlsian account, from what are defined as 'difficulties that need fresh investigation' (p. 66). This distinction implies that the problems in the first category can be re-elaborated within the Rawlsian scheme whereas those in the second category cannot and need an alternative approach. Among the problems in the first category, the following two deserve special attention:

1. The extreme nature of the priority of liberty as conceived by Rawls, and already emphasized by Herbert Hart shortly after the publication of A Theory of Justice. There can be some priority of liberty but not total unconstrained priority. Here the example-presented by Sen on p. 65-of hunger and starvation considered as being worse than a loss of liberty seems inappropriate, because in order to attain Rawls' principles of justice one needs to have realized the so-called 'circumstances of justice' that include moderate scarcity. Given that moderate scarcity is an ambiguous expression - raising the question as to whether rural India reaches the line of moderate scarcity-one should remember that Rawls makes the priority of liberty depend on a minimum average economic well-being of the population. This implies that the priority of liberty does not apply where conditions of hunger and starvation are normal.

2. The fact that Rawls does not provide a way by which primary goods can be converted into good living. In this sense, for Sen, capabilities work better than primary goods, albeit not representing a 'foundational departure' (p. 66) from Rawls' programme. This last comment seems an understatement in the light of Sen's whole argument against Rawls.

Of course, the hard core of Sen's criticism is supposed to rely on the difficulties which cannot be solved within the Rawlsian paradigm. Among them we can list the following difficulties:

1. The relevance of actual behaviour which Rawls is supposed to under-estimate. This problem depends on the strong institutionalism that according to Sen, Rawls is committed to. His theory of justice sees the 'basic structure of society' as its primary subject. As a consequence, the emphasis is on just institutions rather than on a 'just society', with the latter being linked to the actual behaviour of people. As we have already seen, this problem can be also placed in terms of a distinction between a niti approach (Rawls) and a nyaya approach (Sen); 
2. The contractualist approach, which tends to be too limiting (here, I would prefer to apply the term 'contractualist' to 'contractarian', used by Sen, for the KantRawls tradition, leaving the term 'contractarian' for Hobbes' tradition). Sen claims that the contractualist tradition cannot accommodate the following significant possibilities:

- Dealing with comparative assessments instead of identifying transcendental solutions;

- emphasizing social realizations (beyond institutionalism);

- accepting incompleteness in social assessments (a partial ordering can also be alright), and removing manifest cases of injustice on this basis; and

- considering voices beyond the contractualist group that avoid parochialism.

3. The last point listed in (ii) above implies laying a stress on the relevance of global perspectives beyond all that constrains the pursuit of justice within the limits of a determined polity.

Sen pursues all the above criticisms in a long and often detailed manner, which makes it practically impossible to make proper sense of all them here. Still, the most relevant accusations against Rawls can conflate within the niti-nyaya distinction: it is not possible to identify just institutions without making them contingent on the actual behaviour of people. This is, in fact. the reason why Sen's readers are invited to firmly reject Rawls' transcendental institutionalism in the name of Sen's realization-focused comparativism (p.7). It is also interesting to note that some form of anti-institutionalism is typical within the scope of political theory as practised in the Indian academic world. The premise could be either that a weak civil society needs care before entering into the political domain or that institutions recall the State and that the State is seen by many Indian authors as a byproduct of colonialism.

II. It is indeed hard to make a choice between transcendental institutionalism and realization-focused comparativism because, as I said, Sen inflates his thesis with an enormously large number of arguments (whose total is supposed to count against that by Rawls). This makes it extremely difficult to adjudicate the case. For example, it is doubtful to say, as Sen does, that transcendental institutionalism makes the relevance of the global impossible, given that there are many authors like Thomas Pogge, who are simultaneously globalist and institutionalist. The idea according to which democracy as the exercise of public reason (that is the way in which Sen defines democracy) is excluded by the Rawlsian approach is also highly questionable. This criticism originates in a well-known criticism by Habermas of Rawls, as elaborated by the 1995 exchange between the two in the Journal of Philosophy. Elsewhere, I have tried to show how controversial Habermas' point is and how it can also be transitively extended to Sen's point (see Habermas, 1995, pp. 109-31; Maffettone, 2010, chapter 7). Finally, Sen's main criticism-the one based on the niti-nyaya distinction-seems to put together the following three different arguments:

1. A kind of anti-institutionalism à la G.A. Cohen;

2. A thesis against Rawls' purely ideal theory-based approach; and 
3. The idea that 'resourcism' is insufficient because we should rather consider the resources-persons relationship (this is similar to the classical capabilities versus primary goods argument, as made by Sen).

It is also worth noting that the Cohen-like approach-as per point (i) aboverequires more 'ideal theory' and less connection with the facts (it requires facts-free principles). It thus goes in the opposite direction of the claim for realism made under point (ii) above.

However, my remarks here are not intended to minimize the impact of Sen's arguments. It is probably true that a social contract approach à la Rawls makes global legitimation hard. And the strong liberal institutionalism of Rawls can actually make the integration with democracy as deliberation more difficult than necessary. On this last point, Sen devotes a whole chapter to show how the social choice-based approach is much better than the social contract approach. Frankly, I doubt whether Sen has demonstrated here that the social choice theory and democratic deliberation go so well together, but again this is not the real focus of the controversy, which, I repeat, corresponds to the niti-nyaya distinction mentioned above. Sen's main criticism stands or falls with it. That is why in the following discussion, I will try to reduce Sen's mountain of criticisms against Rawls to a smaller but decisive problem. In so doing, my intention is to show that the therapy (Sen's alternative) creates more problems than the initial supposed disease (Rawls' position).

III. In order to proceed in this direction, I claim that the first two parts of Sen's pronyaya anti-niti argument can be substantially reduced to the third one: Cohen's anti-institutionalism and the objections to a mere ideal theory-based approach, are dependent on-and anyway secondary to - the 'resources' versus 'resources related to people' (id est capabilities) thesis. In other words, both these criticisms converge into the third, according to which Rawls defends institutionalism too easily by making extremely strong assumptions on the post-contract behaviour of the persons and assumptions that are less strong than necessary on the pre-contract attitudes. This erroneous path can be avoided only by taking persons seriously in a more direct way. To sum up all these arguments, and to reduce them to one, we could say that Sen's main disagreement with Rawls lies in the thesis that fairness should also properly apply to persons whereas Rawls' principles apply only to institutions. And this is exactly why the capability thesis reproaches the resourcist approach à la Rawls.

If we look at Chapter 12 of this book, entitled 'Capabilities and Resources', we can see how this opposition is relevant for Sen. Here, resources are considered as being analogous to wealth, with both being "not something we value for its own sake" (p. 253). Capabilities, on the other hand, being linked with substantive freedom, focus on the actual ability to do different things that a person values. For example, a person with a large amount of wealth cannot be considered advantaged if she suffers from a severe disability. Rawls's primary goods-and more generally all resourcist approachesare for Sen 'feticist' because they wrongly consider primarily means where they should rather consider ends. For Sen, this mistake becomes transparent if we examine 
poverty. Poverty cannot be properly understood just in terms of income (or wealth, for that matter). Of course, an index of primary goods represents a vector, which is why it includes more than income (or wealth), but its analysis is still guided by a 'search for general all purpose means' (p. 254). Sen claims that this is wrong because what really counts is the way in which different persons convert income or primary goods (more generally, resources) into good living. thus, poverty is contingent upon the different characteristics of people and of the environment in which they live. Disabilities constitute another relevant example because they clearly point to a difficulty in the conversion of resources into capabilities. Poverty and disabilities instantiate an evident 'conversion handicap' (p. 258). The thesis, however, aims to be more general, and does not apply only to them.

This thesis makes Sen sceptical about Rawls' difference principle, which notoriously concentrates upon primary goods to settle distributional issues. The idea here is that even if Rawls recommends-in line with a 'principle of redress'-correctives for 'special needs', this is not enough because the problem of the conversions of primary goods (and generally resources) into good living is structural and ubiquitous. That is why this very problem implies a "departure from Rawlsian theory" (p. 262). This departure is directed toward a theory-like the capability theory (unlike that in resourcism)-in which the focus is on the ends rather than the means.

Given these premises, it is not surprising that Sen-in Chapter 13-takes into consideration happiness in its relationship with well-being and capabilities. In fact, here we have a kind of utilitarian turn, implied by Sen's main argument (that is, the nyaya versus niti argument). After all, the main characteristic of utilitarianism consists in focusing on the relationships between goods and persons, whose psychological reactions in terms of happiness are what eventually count. Moreover, Sen stresses the importance of outcomes and realizations in opposition to Rawls's preference for the centrality of an interpersonal agreement. And such a difference approximates the traditional distinction between the utilitarian and contractualist outlooks.

Sen indeed recognizes that the recent emphasis of economic science on happinesswith which he sympathizes-has origins in the once-dominant utilitarian tradition, and here the anti-Rawlsianism reaches its climax. He also points out that a "substantial part of welfare economics is still largely utilitarian" (p. 272). These admissions are not surprising, because if one is in search of ends rather than means, happiness is a plausible final destination, simply because it is by definition an ultimate goal.

This conclusion prima facie seems to give us some advantage, but on reflection, it is difficult to ignore its inconveniences, which are epistemic and ethical-political, and can be summed up in the following contention-unless we know people's values and tastes, which is improbable, there is a significant risk of paternalism when we consider happiness as the last word in this argument ${ }^{3}$. This is why -in A Theory of Justice, Rawls contrasts his liberalism with a liberalism of happiness, which is a kind of perfectionist and paternalistic vision. In the book, Sen himself admits the risk of paternalism, and also quotes Richard Layard in this sense (see Layard, 2005). It is also easy to observe 
that the happiness economics shares the danger of paternalism and consequently creates, for a liberal, problems that are analogous to the ones implied by utilitarianism (as shown by Rawls in A Theory of Justice).

I will come back to the danger of paternalism later, a danger that I think is implicit not only in the very notion of happiness, but rather in the whole capability approach because here I prefer to focus on Sen's trajectory in the book. Sen, in fact, seems alert about this danger, in particular when (pp 277 and ff) he tracks the origins of welfare economics in the desire to separate itself from utilitarianism. The reason for this desire can no doubt be found in the will to attain more epistemic abstinence, due to the fact that interpersonal comparisons of utility imply value judgments and are often difficult to assess. Sen easily dismisses by stressing that we normally compare "joys and pains of human life" (p. 277). What seems strange is that he does not consider the hypothesis that in so doing, he is here defending something (social choice plus interpersonal comparisons) that is similar to utilitarianism as opposed to Rawlsian liberalism. Of course, in order to distinguish his position from utilitarianism, Sen claims to be antiwelfarist, a position that he considers not narrowly confined to the utilities. But we are still within a utilitarian framework in the broad sense.

Sen devotes a section (pp. 279 and ff) to the way in which welfare economics separated itself from utilitarianism, following Lionel Robbins' first (epistemic) criticisms of utilitarianism. In this process, welfare economics took the form of the social choice theory à la Arrow, an approach that Sen masters better than anyone else. In his seminal book, Social Choice and Individual Values, Kenneth Arrow, quoted by Sen (p. 279), formulated the viewpoint according to which 'interpersonal comparisons of utilities have no meaning'. This implies that the levels of utility or happiness cannot be compared among different people. And all these informational restrictions leave us - within the realm of welfare economics - with a set of decision procedures that are roughly similar to voting (p. 280). This conclusion implies that within classic welfare economics, we cannot make any use of the happiness metric to discuss inequality and equity. Sen does not accept this prudent conclusion. In order to avoid it, he reconsiders some of his own past work on collective choice theory, in particular the part in which he connected Arrow's impossibility result to the meaninglessness of the interpersonal comparability within Arrow's paradigm.

Since the 1970s, Sen has given a strategy to take Arrow's impossibility seriously and to look for devices that would enable us to avoid it. Within this strategy, enriching the informational basis of the collective choice procedure seems a necessary step. This move, of course, relocates us in proximity to the utilitarian tradition. However, Sen-and here he separates himself from full and simple utilitarianism-thinks that utilitarianism is not a good guide in this direction due to the fact that utilitarianism limits its informational apparatus to welfare information. Welfarism, however, is troubling for Sen, particularly because it neglects all information concerning freedom and agency. Moreover, the utilitarian calculus, based on happiness and desire fulfilment, can be unfair toward "those who are persistently deprived" (p. 282). These people can, in fact, cultivate adaptive preferences, tending to adjust their desires to 
actual circumstances to make their life more bearable. In this way, we cannot rely on the interpersonal comparisons of utilities based on their natural preferences.

Sen points out that the very concept of capability is supposed to overcome this difficulty by taking into consideration well-being in the optics of substantive freedom. This result derives from the fact that for Sen, an assessment of capabilities must start with two important distinctions: firstly, between freedom and agency; and secondly, between freedom and achievement. This dynamics introduces procedural elements connected with fairness in an otherwise consequentialist (albeit not welfarist) paradigm. I do not doubt that taking note of agency achievements or agency freedom "shifts the focus away from seeing a person as just a vehicle of well-being" (p. 288), thereby permitting Sen a detachment from what could be generally interpreted as a quasi-utilitarian framework. But perhaps this is not the point. The problem here consists rather in seeing whether the shift Sen that takes from means to ends, from procedures to outcomes, from epistemic prudence to the acceptance of interpersonal comparisons, still allows one to remain immune to some of the risks that are usually connected with utilitarianism.

Curiously enough, these risks have been stressed in the past by both Sen and Rawls. In Chapter 8 of his masterful book, Collective Choice and Social Welfare (1970), Sen faces the usual conundrum of avoiding Arrow's impossibility by starting with problems of distributive justice from the point of view of the collective choice theory. His strategy is based on the idea of enriching the information available to the decisionmakers. This enrichment of information is usually connected with the measurability of individual welfare (this measure can be ordinal or cardinal) and the interpersonal comparability of these judgements (that can either be admitted or not admitted in the calculus), not speaking here of the form of the function we take in consideration (see p. 118 and ff of Collective Choice and Social Welfare [CCSW]). In theory, we could enrich information in two ways: either by assuming cardinal measurability of the preferences or by allowing interpersonal comparability among the decision-makers. After a powerful demonstrative tour de force, however, Sen concludes that what really counts are interpersonal comparisons: even if we use the cardinal instead of ordinal measure, like Arrow did, Arrow's impossibility is still there. "The crucial difference lies in introducing comparability" (CCSW, p. 124), which means, for example, that ordinal comparability can bypass Arrow's impossibility whereas cardinal noncomparability cannot. Rawls' original maximin solution introduces a limited ordinal comparability whereas utilitarianism is in favour of complete cardinal comparability. Now, it seems that Sen's argument for capabilities moves toward this second option. But, as Sen himself has shown many times, such informational basis is epistemically very demanding.

The main problem with interpersonal comparisons is, however, not epistemic but rather ethical-political, at least if one moves within a broadly speaking liberal horizon. This is the reason why I spoke of paternalism. The large quantity of information that the nyaya approach requires is not usually available, and on many occasions, can be imposed from outside (actually this is so except in extraordinary cases, which I will 
come back to later). Such a conclusion makes us understand the main danger of this approach. If the nyaya approach implies a paternalistic imposition of preferences upon the individual decision-makers, then the autonomy of people is at risk. Obviously paternalism is at odds with liberalism. I am just stressing that Sen's nyaya approach approximates paternalism, whereas a more prudent niti approach is more naturally coherent with liberalism.

This conclusion is not particularly surprising, if not for other reasons than because Rawls timidly formulated a similar analysis in Political Liberalism, and Sen himself partly recognizes such a danger in this book. In the Lecture V of Political Liberalism, Rawls aims to show that the choice of an index of primary goods as a reference for his own second principle of justice depends on what he calls a 'political conception'. The political conception that Rawls has in mind is a liberal conception whose fundamental goal consists in defending pluralism within the limits of stability. Within this perspective, justice as fairness has to reject "the idea of comparing and maximizing overall well being in matters of political justice" (Political Liberalism [PL], p 188). This is why primary goods imply some general means that are able to satisfy the needs of citizens when questions of justice arise. Such a construct depends-within a liberal political conception like that of Rawls-on a thin theory of the good, with the intention of preserving the (liberal) autonomy of the citizens. To do otherwise would imply the use of a comprehensive doctrine, which is exactly what a political conception à la Rawls is supposed to avoid.

Now, there is no doubt that an index of primary goods like that of Rawls "does not approximate very accurately what many people must want and value as judged by their comprehensive views" ( $P L$, p. 189). But here incompleteness is the price we pay for neutrality. The trade-off between liberty and preference satisfaction is meant to avoid paternalism within the political ambit. It presupposes-as Rawls says-"a social division of responsibility" ( $P L$, p. 189), within which the political sphere provides general omni-potential means while the rest-including some very significant ends-are left to individuals and associations. To do otherwise-as every liberal person knows-would imply politically imposing, via coercion if necessary, what are perhaps important but surely controversial ends. Putting it bluntly, to claim that politics should pursue fundamental ends would be to misrepresent politics like a form of applied ethics. This is not so, within a liberal political conception like that of Rawls, in which the priority of the political makes it partially independent from the claims of ethics. Only individual persons, and their free associations, and not political institutions, can take responsibility for their ends.

In his book, Sen is not unaware of this problem, even if he under-estimates its ethical-political relevance. In Chapter 14 of the book, he uses the capability approach to comparatively assess the well-being of persons. This leaves room for many other, mainly procedural, concerns. In a footnote (p. 297), Sen also includes among these other concerns, which are, according to himself, part of Rawls' conception, "personal liberties and the need for fair procedures". Fair enough! one could say, if not for the fact that there could be a conflict between the general logic of the capability approach and 
these other concerns. According to Sen (and again the reference here is to Rawls' theory of justice), "the contrast between primary goods and capabilities is in a limited arena" (p. 299) and only there. The rest, in particular the status of liberty and the demands of procedural fairness, can be left to Rawls' theory. Now, my question is: Is this possible and plausible? Perhaps not. The very logic of capabilities could be in conflict with the logic of political liberalism, due to the fact that political liberalism requires one to avoid the interpretation of people's ends. Sen, via capabilities, transforms (in part) politics into a form of applied ethics wherein the good dictates the nature of the right. This is more or less like what the utilitarians do, and that is at odds with liberalism. This is also the reason why Sen's nyaya-based approach in the end runs the risk of paternalism.

IV. Having said all this, I must admit that, even if I remain unconvinced by Sen's general argument, there is still a part of it that could well integrate a liberal vision like that of Rawls. My thesis presupposes that people's preferences and desires, especially if we have in mind large numbers, are generally opaque. Perhaps you can successfully try to share some of your goods among your offspring, assuming that in this case, you have a deep personal knowledge of the people concerned. However, to operate in a similar way with the entire population of a polity, for example if you were the Ministry of the Treasure, when one would be working under a "thick veil of ignorance", would preposterous and risky. This is why any effort to try to realize ends where people are concerned, such as comparing their different tastes and values via politics-like Sen wants-implies some form of paternalism and can be taken as being anti-liberal. However, it is not always so. There are cases in which the desires and preferences of people do not look like opaque. If you think of situations of hunger and starvation or severe diseases, you understand why. In such cases, people's desires and preferences are usually transparent: they just want food and to be cured. Here, it is easy and not paternalistic to guess what people want and consequently to argue that we should try to help them convert their needs into new substantive opportunities. Sometimes, it could even be wrong to try not to interpret people needs: for instance, if one were to arrive at Dachau in 1945, it would not need a special ability to understand that prisoners must be helped!

This is another way of saying something more general: that to make public sense of interpersonal comparisons, we need some a priori consensus, like when 'urgency' to use a well-known term of Thomas Scanlon-is at the stake. When we make interpersonal comparisons, we compare the goodness of the individual $\mathrm{i}$ in situation A with the goodness of the individual $j$ in situation B. The question here concerns the way in which judgements of this type must be conceived. The problem with utilitarianism in assessing these judgments lies in its dependency on the subjective experiences of $i$ and $j$. We are familiar with examples in which $i$ is depressed whereas $\mathrm{j}$ is a sort of utility monster. All these imaginary possibilities render the utilitarian way of making interpersonal comparisons arbitrary from a public point of view. This impression forces the thesis that we should rely on some objective standard other than the simple preferences of $i$ and $j$ themselves. 
This is why public justification via interpersonal comparisons presupposes urgency, and (only) when there is urgency can we grasp the meaning of people conversion handicaps, and consequently, we can accept the idea that, for instance, disabled and hungry persons should be given more adequate "functionings" to live with. Here, the capability approaches work by avoiding the danger of paternalism ${ }^{4}$. In this light, it is not surprising that many of the examples cited by Sen concerning the limits of resourcism come from cases wherein we are confronted with persons who are affected either by severe diseases or by extreme poverty.

The conclusion of the last paragraph offers the possibility of a reconciliation between the two paradigms that I have been discussing, namely those of Rawls and Sen. We can draw an imaginary line that separates the 'normally cooperating members of society' (Rawls) on one side from persons who are not so lucky, on the other side. Above this line, people can well be treated by liberal political theories à la Rawls. Underneath this line, however, it is not so. People living clearly underneath the line are doing so in conditions of 'urgency', and, therefore, deserve special attention, and for them liberal neutrality is not enough. The notion of 'urgency' or 'importance' implies a criterion through which we can objectively discriminate among strong preferences. Thomas Scanlon describes rather than defines urgency in terms of comparability among goods and satisfactions connected with them. For example, health is more important than amusement. Together with health and amusement, we have other concerns, and we can hypothesize in associating with them a multi-level scale wherein various combinations of such levels represent different levels of well-being. "The relation of urgency, then, will be a relation between various increments and decrements along one or more of these scales" (see Scanlon, 2003a.). Again Scanlon, commenting on the nature of (Rawlsian) contractualism, writes that "under contractualism ...our attention is naturally directed first to those who would do worst" (see Scanlon, 2003b). He also presents this moral option of contractualism in contrast with the nature of utilitarianism, because the 'losers' are not sufficiently cared for within any utilitarian maximization of aggregate well-being. Rawls himself indeed goes in this direction when in Political Liberalism (pp. 184 and ff) he tries to meet Sen's challenging objections to his own view of primary goods. But he never generalizes this thesis.

The notion of urgency seems to be an attractive bridge between the views of Rawls and Sen. Urgency is presented by Scanlon under the edge of a doctrine that is capable of comparatively assessing benefits and burdens from the point of view of political morality. Thus conceived, this doctrine is required to satisfy the following three properties: (I) it must represent a kind of consensus among those to whom justification is addressed; (ii) it must allow for the fact that individuals have different tastes and interests; and (iii) it must be result-oriented. For Scanlon, such a doctrine cannot be formulated in terms of subjective criteria like many utilitarian would do so while basing their models on preference satisfaction. On the contrary, it requires an objective criterion that is coherent with our objective idea of moral judgement. Of course, we are required to declare on what basis we can discriminate among preferences of different persons. Urgency is one of these required bases. Urgency, as we have seen, is assessed 
in terms of increments or decrements along the different scales on which we locate our concerns. The idea is that once we begin to understand the desirability of the benefits and the in-desirability of the burdens at stake, we can create a "hierarchy of relative urgency" Interestingly enough, this conception of urgency is rather like nyaya to use Sen's terminology, in the sense that it depends on the comparisons among different lives in various contexts. Moreover, the example given by Scanlon focuses on those with "expensive medical needs" (see Scanlon, 2003a), which is altogether coherent with Sen's vision.

More generally, one could say that Rawlsian institutionalism can work like an obstacle when frontier questions (concerning the disabled, foreigners) are at stake. Take, for instance, global justice, an issue that Sen emphasizes. Here, the difficulties of a liberal Rawlsian paradigm-made evident by Thomas Nagel-derive from the necessity of this paradigm to neatly separate ethics from politics (see Nagel, "The Problem of Global Justice", 2005, reprinted in Nagel, Secular Philosophy and the Religious Temperament, 2010). Within a Rawlsian view, political justice, that is, the main business of the theory, must be coherent with the basic structure of the society that it addresses. With this basic structure comprising a network of institutions, political justice presupposes reliable institutions. In the global domain, however, institutions are often not reliable from the point of view of justice. This makes the ethical appeal, which is implicit in the idea of justice, contrast with its political basis. While we know that global justice is needed, we do not know how to make it properly political. ${ }^{5}$ Sen indicates that the nyaya path can function here as a strategy emanating from our ethical intuitions, which are supposed to be in favour of global justice, to the construction of a renewed basic structure that is more coherent with global justice than the actual one. Sometimes, ethical evidence must anticipate the political structure. This applies, in a vague and provisional sense, whenever human inter-subjective relations create substantive problems of justice that are unable to receive an immediate institutional response. It is extremely pertinent in case of urgency (think, for instance, of the Holocaust). For a Rawlsian liberal, global justice signifies a case that fits the dialectics between ethics and politics that I have been alluding to. The indication we can draw from Sen is that in all these cases, we should take serious consideration of the relation between human needs-presupposing lives in contexts-and institutions.

We could also investigate further and more general (going beyond urgency) possibilities of reconciliation between the paradigms of Rawls and Sen that I have discussed. While thinking of them, it is difficult to avoid the impression that Rawls' theory of justice comes from a wealthy nation, and is inevitably tied to its US origins. In a country like the US, protecting liberty as an individual choice is perhaps more important than elsewhere, for example, it could be more important than in rural India or Africa. This implies that whenever we expand the original Rawlsian paradigm from the US setting to other parts of the globe or to a particular region within it, we should be more careful in redesigning the relation between persons and institutions. This is, after all, what Sen recommends. It is almost superfluous to say that my intention in saying this is not to transform political theory in a kind of sophisticated moral 
geography. It is rather an invitation to take history and tradition more seriously than many analytically trained political theorists usually do. I imagine indeed that such an argument would be coherent not only with Sen (from whom it is derived) but also with Rawls. If we carefully consider Rawls' vision of justice, we would note that the foundational concept of the basic structure must not be an invariant. It is rather a historical notion that presupposes a strong link between civil society and institutions.

Finally, the social contract strategy à la Rawls proposes an objective criterion to discriminate among the preferences of different people. This criterion can be based on a hierarchy of relative urgency and can also be made wide enough to include a set of frontier situations. In difficult circumstances, we can comparatively assess people's well-being in terms of nyaya, but coherently with a general liberal outlook. But, for the rest, we need to reject neither institutionalism nor contractualism. Perhaps, we can also use - albeit in quite a vague way — the nyaya approach to expand the possibilities associated with a too severe institutionalist approach in the direction of a more human centred view. Perhaps when we want to extend the natural ambit of Rawls' theory of justice, by applying it to problems of global justice, we must follow nyaya, or at least reformulate the fundamentals of the theory from the point of view of relations between people and institutions. In the light of Sen's often inspiring book that I have been discussing, one could conclude by saying that even if a liberal should be normally coherent with a niti-based view, there are significant categories classes of cases in which it is not so and a liberal should become more coherent with a nyaya-based view.

\section{ACKNOWLEDGEMENTS}

I thank Luciano Andreozzi, Gianfranco Pellegrino and Aakash Singh for their precious comments on the first version of this paper. The paper has been elaborated in view of a discussion held at the India International Centre in Delhi on 12 January 2011. I thank Akeel Bilgrami and Neera Chandhoke for this discussion. The paper has also been presented, in part, at Baruch College (CUNY, New York) on 24 February 2011 and at San Diego State University on 28 February 2011. I thank Benedetto Fontana and Darrell Moellendorf for their invitation to present the paper and for their comments. Finally, I would also like to thank Ronald Dworkin and Joshua Cohen, as informal discussions with them also contributed to the final version of the paper.

\section{NOTES}

1. Sen confronts himself with Rawls, whose main works considered here are A Theory of Justice, 1971, and Political Liberalism, 1996 (second edition).

2. In some way, here-like in the rest of this book-Sen's attitude toward Rawls is ambiguous: one never understands how much Sen is willing to distance his own approach from that of Rawls.

3. To be analytical, one should clearly separate the epistemic and the ethical-political side of paternalism. Unfortunately, such an internal distinction is not easy. It would, in fact, be complicated to go within the analysis of the epistemic side of the problem (one can get some help by reading Feldman, 2010) and would require elements of empirical psychology. In his Political Liberalism, Rawls, rather vaguely, connects the 'burdens of judgments' with pluralism. Here, I limit myself by arguing that we can assume some relation between the two aspects-epistemic and ethicalpolitical - of paternalism by going within the argument. I hope that this strategy can be forgiven, if one considers that I am not particularly interested here in the epistemic side of the issue. 
4. Perhaps we should distinguish between two different forms of paternalism. On one hand, we can have paternalism toward the victims, like for example, starving or disabled people. On the other hand, we can have paternalism toward the normal citizens, for example, if they are obliged to pay taxes to help starving or disabled people. In the second case, the risk of paternalism implies the compulsory transformation of a super-erogatory sentiment in an obligation, and consequently, runs the risk of over-demandingness.

5. Rawls himself says in A Theory of Justice, pp. 352-53, that when circumstances of justice are not realized and we are in severe distress, contractualism becomes very similar to utilitarianism.

\section{REFERENCES}

Arrow, Kenneth (1979). Social Choice and Individual Values, North Holland, Amsterdam.

Feldman, F. (2010). What Is This Thing Called Happiness?, Oxford University Press, Oxford.

Habermas, J. (1995). "Reconciliation through the Public Use of Reason: Remarks on John Rawls' Political Liberalism", Journal of Philosophy, Vol. 92, No. 3, March, pp. 109-31.

Layard, R. (2005). Happiness: Lessons from a New Science, Penguin, New York.

Maffettone, S. (2010). Rawls: An Introduction, Polity Press, Cambridge.

Nagel, Thomas (2005). "The Problem of Global Justice", Philosophy and Public Affairs, Vol. 33, No. 2, pp. 113-47.

(2010). Secular Philosophy and the Religious Temperament Essays 2002-2008, Oxford University Press, Oxford.

Rawls, John (1971). A Theory of Justice, Harvard University Press, Cambridge, MA.

_ (1996). Political Liberalism, Columbia University Press, New York.

Scanlon, Thomas (2003a). "Preference and Urgency", in Thomas Scanlon, The Difficulty of Tolerance: Essays in Political Philosophy, Cambridge University Press, Cambridge, pp. 70-83.

Scanlon, Thomas (2003b). "Contractualism and Utilitarianism", in Thomas Scanlon, The Difficulty of Tolerance: Essays in Political Philosophy, Cambridge University Press, Cambridge, pp. 124-50.

Sen, Amartya (1970). Collective Choice and Social Welfare, North Holland, Amsterdam.

- (2009). The Idea of Justice, Penguin, London. 


\section{INDIAN JOURNAL OF HUMAN DEVELOPMENT}

Volume 5

Number 1

January-June 2011

The Indian Journal of Human Development:

$>$ welcomes original inter-disciplinary contributions from a human development perspective on developing countries

$>$ promotes fresh debates on concepts and measurement of human development

$>$ explores the inter-connections between policy interventions and impacts on the lives of people

$>$ includes a comparative analysis of development policies that enhance people's freedoms

$>$ offers human development insights into policy analysis and evaluation

The Journal includes scholarly essays and short comments, lectures and orations, reflections and perspectives, book reviews, information on events and statistics relating to human development. Expressions of all shades and opinions are welcome.

\section{Subscription Rates}

\begin{tabular}{|c|c|c|c|}
\hline & India & South Asia & Other Countries \\
\hline \multicolumn{4}{|c|}{ INDIVIDUAL } \\
\hline Annual & Rs. 400 & US $\$ 40$ & US\$ 75 \\
\hline Three Years & Rs. 1100 & US\$ 110 & US\$ 205 \\
\hline Five Years & Rs. 1750 & US\$ 175 & US\$ 350 \\
\hline \multicolumn{4}{|c|}{ INSTITUTIONAL } \\
\hline \multicolumn{4}{|c|}{ Annual } \\
\hline Print + Online & Rs. 600 & US\$ 60 & US\$ 120 \\
\hline Print Only & Rs. 550 & US\$ 55 & US\$ 115 \\
\hline Online Only & Rs. 500 & US\$ $\$ 50$ & US\$ 105 \\
\hline \multicolumn{4}{|c|}{ Three Years } \\
\hline Print + Online & Rs. 1700 & US\$ 170 & US\$ 350 \\
\hline Print Only & Rs. 1600 & US\$ 160 & US\$ 340 \\
\hline Online Only & Rs. 1500 & US $\$ 150$ & US\$ 330 \\
\hline \multicolumn{4}{|c|}{ Five Years } \\
\hline Print + Online & Rs. 2750 & US\$ 275 & US\$550 \\
\hline Print Only & Rs. 2600 & US\$260 & US\$ 535 \\
\hline Online Only & Rs. 2500 & US\$2 250 & US\$ 525 \\
\hline
\end{tabular}

\section{Institute for Human Development}

NIDM Building, IIPA Campus, IP Estate

New Delhi-110 002

Phones: +91-11-23358166/ 23321610

Fax: +91-11-2376 5410

Email: ijhd@ihdindia.org

Website: www.indindia.org

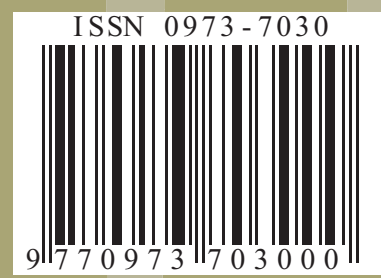

